\title{
In reply: Apneic oxygenation during emergency airway management
}

\author{
Edmund Tan, BSc, MD, FRCPC (D) - Osama Loubani, MD • Nelofar Kureshi, MBBS • \\ Robert S. Green, MD
}

Received: 10 July 2018/Accepted: 10 July 2018/Published online: 15 August 2018

(C) Canadian Anesthesiologists' Society 2018

\section{To the Editor,}

We thank Dr. El-Orbany for the comments regarding our paper on the use of apneic oxygenation (AO) to prevent oxygen desaturation during emergency intubations. ${ }^{1}$ While our paper suggested a potential benefit of $\mathrm{AO}$ using nasal cannulae to prevent oxygen desaturation, ${ }^{2}$ we agree that $\mathrm{AO}$ is not a replacement for good preoxygenation. Preoxygenation is the gold standard in preventing oxygen desaturation during intubation. ${ }^{3}$ In all identified studies, each participant group received preoxygenation prior to intubation and AO was used as a supplementary technique to prevent oxygen desaturation. As outlined in the review, different types of preoxygenation were used in each investigation and preoxygenation may have been different in the control group compared with the intervention group, depending on the study. The differences in preoxygenation technique may have influenced the results of each study, but it was not possible to determine this from the evidence presented. $^{2}$ This discrepancy highlights the need for a standardized preoxygenation technique to assess the benefits of $\mathrm{AO}$ in emergency intubations.

Regarding the analysis of other AO methods, such as the oral or buccal route, we recognize that these techniques prolong the time to oxygen desaturation in the operating room. ${ }^{4}$ Nonetheless, to date no study has examined these $\mathrm{AO}$ techniques in the emergency intubation setting. For this reason, studies on other AO methods were excluded from our analysis.

Conflicts of interest None declared.

Editorial responsibility This submission was handled by Dr. Hilary P. Grocott, Editor-in-Chief, Canadian Journal of Anesthesia.

\section{References}

1. El-Orbany M. Apneic oxygenation during emergency airway management. Can J Anesth 2019; 66. DOI: https://doi.org/10. 1007/s12630-018-1188-x

2. Tan E, Loubani $O$, Kureshi N, Green RS. Does apneic oxygenation prevent desaturation during emergency airway management? A systematic review and meta-analysis. Can J Anesth 2018. DOI: https://doi.org/10.1007/s12630-018-1124-0.

3. Tanoubi I, Drolet $P$, Donati F. Optimizing preoxygenation in adults. Can J Anesth 2009; 56: 449-66.

4. Heard A, Toner AJ, Evans JR, Aranda Palacios AM, Lauer S. Apneic oxygenation during prolonged laryngoscopy in obese patients: a randomized, controlled trial of buccal RAE tube oxygen administration. Anesth Analg 2017; 124: 1162-7.

E. Tan, BSc, MD, FRCPC $(\bowtie) \cdot$ O. Loubani, MD .

N. Kureshi, MBBS - R. S. Green, MD

Departments of Critical Care and Anesthesia, Dalhousie

University, Halifax, NS, Canada

e-mail: cetan@dal.ca 